\title{
ASSISTÊNCIA ESTUDANTIL: A Implementação do Programa.
}

\author{
JULIANA FERNANDA DA SILVA ${ }^{1}$ \\ ${ }^{1}$ Instituto Federal de Educação, Ciência e Tecnologia de São Paulo (IFSP) \\ $<$ social.juliana@yahoo.com.br>
}

DOI: 10.21439/conexoes.v10i1.793

\begin{abstract}
Resumo. O contexto educacional brasileiro apresenta mudanças significativas desde o início do século XXI, com a ampliação do acesso de estudantes ao ensino técnico e superior. Estas transformações requerem uma atenção à permanência destes estudantes na instituição de ensino e tem entre suas ações o programa nacional de assistência estudantil, que objetiva democratizar as condições de permanência dos jovens na educação pública federal, minimizar os efeitos das desigualdades sociais e regionais na permanência e conclusão da educação, reduzir as taxas de retenção, evasão e contribuir para a promoção da inclusão social pela educação. Este artigo objetiva uma compreensão da assistência estudantil a partir de uma abordagem teórica realizada por meio de estudo bibliográfico e documental, concluindo que a assistência estudantil deve viabilizar a igualdade de oportunidades na permanência do estudante na educação.
\end{abstract}

Palavras-chaves: Assistência Estudantil. Programa. Permanência. Evasão. Educação.

\begin{abstract}
The Brazilian educational context has changed significantly since the beginning of the XXI century, with the expansion of student access to technical and higher education. These transformations requires attention to these students stay in School and has among its actions national student assistance program, which aims to democratize the conditions of stay of youth in the federal public education, minimize the effects of social and regional inequalities remain and completion of education, lower retention rates, dropout and contribute to the promotion of social inclusion through education. This article aims at an understanding of student assistance from a theoretical approach carried out by means of bibliographical and documentary study, concluding that the student assistance should enable equal opportunities in the student's stay in education.
\end{abstract}

Keywords: Student Assistance. Program. Residence. Evasion. Education.

\section{INTRODUÇÃO}

Constata-se na educação brasileira a ampliação do acesso de estudantes ao ensino técnico e superior, contribuindo para este fator o processo de expansão das instituições federais de ensino, a utilização da nota do Exame Nacional do Ensino Médio - ENEM 11 pelo Sistema de Seleção Unificado - SISU2 ${ }^{2}$ como forma de acesso aos cursos oferecidos na rede federal de educação, além do incentivo pelo governo federal via con-

\footnotetext{
${ }^{1}$ O ENEM foi criado em 1998 com o objetivo de avaliar o desempenho do estudante ao fim da escolaridade básica, é utilizado ainda como critério de seleção para ingresso no PROUNI e SISU.

${ }^{2}$ A portaria normativa $\mathrm{n}^{\mathrm{o}} 21$, de 05 de novembro de 2012 , dispõe sobre o SISU, que é o sistema informatizado gerenciado pelo Ministério da Educação - MEC no qual instituições públicas de ensino superior oferecem vagas para candidatos participantes do Exame Nacional de Ensino Médio (BRASIL, 2012c).
}

cessão de bolsas de estudo pelo Programa Universidade para Todos - PROUNI (BRASIL, 2005b) e por meio de financiamento estudantil através do Fundo de Financiamento Estudantil - FIES.

Outro fator de mudança nas instituições federais de ensino é a lei n ${ }^{\circ} 12.711$ de 29 de agosto de 2012 (BRASIL, 2012a), que dispõe sobre o ingresso nas universidades federais e nas instituições federais de ensino técnico de nível médio e dá outras providências. Em outubro foi publicado ainda o decreto $\mathrm{n}^{0} 7.824$ de 11 de outubro de 2012 (BRASIL, 2012b) regulamentando a lei.

Estas mudanças conjunturais têm relação direta com o programa de assistência estudantil, já que carecem de ações que garantam a permanência do estudante nas instituições de ensino. 
ASSISTÊNCIA ESTUDANTIL: A Implementação do Programa

O decreto $n^{\circ} 7.234$ de 19 de julho de 2010 (BRASIL, 2010) dispõe sobre o Programa Nacional de Assistência Estudantil - PNAES e tem como finalidade ampliar as condições de permanência do estudante na educação pública federal.

Executado no âmbito do Ministério da Educação MEC, o programa nacional de assistência estudantil, objetiva a efetivação da educação como direito social, fundamentando-se na equidade de oportunidade de permanência aos estudantes.

A implantação das ações de permanência e do programa nacional de assistência estudantil faz parte de uma intensa luta pela efetivação da educação como um direito social.

Essa realidade indica aspectos que precisam ser conhecidos e debatidos, principalmente relacionados à realidade social em que emergem. Este trabalho baseiase em uma pesquisa bibliográfica e documental acerca da implementação do programa de assistência estudantil na educação profissional e tecnológica.

\section{OBJETIVO}

Este artigo objetiva a compreensão da assistência estudantil e sua implementação na educação profissional e tecnológica analisando a ampliação do acesso e a necessária implementação de uma política de permanência na instituição de ensino federal.

Recentemente acompanha-se uma série de medidas relacionadas à ampliação do acesso de estudantes ao ensino técnico e superior no país.

A nota do Exame Nacional do Ensino Médio ENEM começou a ser utilizado pelo Sistema de Seleção Unificado - SISU como forma de acesso aos cursos oferecidos na rede federal de educação, especificamente nos cursos de ensino superior, aumentando a mobilidade socioterritorial, já que o vestibulando pode realizar a prova em sua cidade de origem e disputar uma vaga no ensino público federal em município e estado distinto do seu.

O aumento no acesso ao ensino superior também está sendo estimulado pelo governo federal via concessão de bolsas de estudo pelo Programa Universidade para Todos - PROUNI (BRASIL, 2005b) e por meio de financiamento estudantil através do Fundo de Financiamento Estudantil - FIES. Dados do SEADE confirmam que:

[...] O acesso dos jovens de 18 a 24 anos no ensino superior ampliou-se expressivamente, tanto no Estado de São Paulo como no Brasil. Para a população paulista, esse indicador passou de 7,4\% em 1993, para 17,7\%, em 2012
No Brasil, a evolução foi de $4,8 \%$ para $15,1 \%$ no mesmo período. (SEADE 2014).

Outra questão de mudança nas instituições federais de ensino é a chamada Lei das Cotas, a lei n ${ }^{\circ} 12.711$ de 29 de agosto de 2012 (BRASIL, 2012a), que dispõe sobre o ingresso nas universidades federais e nas instituições federais de ensino técnico de nível médio e dá outras providências. Em outubro foi publicado ainda o decreto $n^{\circ} 7.824$ de 11 de outubro de 2012 (BRASIL. 2012b) regulamentando a lei. Assim, instituiu-se a reserva de $50 \%$ de suas vagas para estudantes que tenham cursado integralmente o ensino médio (para o curso superior) e cursado integralmente o ensino fundamental (para curso de ensino técnico de nível médio) em escolas públicas; explica ainda que no preenchimento das vagas $50 \%$ deverão ser reservadas a estudantes oriundos de famílias com renda igual ou inferior a um salário mínimo e meio per capita; estas vagas devem ainda ser reservadas por curso e turno aos autodeclarados pretos, pardos e indígenas na proporção de vagas no mínimo igual à de pretos, pardos e indígenas na população da unidade da federação onde está instalada a instituição, segundo o último censo do Instituto Brasileiro de Geografia e Estatística - IBGE (BRASIL, 2012a).

Esta é uma lei que gera muita discussão e indispensável ao combate das desigualdades raciais e sociais existentes na sociedade brasileira.

\footnotetext{
Com a abolição da escravidão, aos negros libertos restou a servidão aos estigmas dos séculos de aprisionamento e opressão. Na verdade, os que antes eram escravos continuaram à margem do Estado nacional e de todas as possibilidades de acesso à mobilidade social. O Brasil império em nada se intimidou em oficializar, por decreto, a proibição da educação formal aos negros. Este é um dos fatos que mais levaram ao afastamento da população negra dos círculos sociais, políticos e da produção econômica brasileira, em razão da expressa legalização de normas que impediam a integração cultural e intelectual dos negros no transcorres do século XIX, e com evidentes resistências ainda no século XX (BRASIL 2013b. p. 39).
}

A implantação da lei de cotas e do SISU como medidas de ampliação do acesso às instituições públicas de ensino federal têm relação direta com o programa de assistência estudantil, já que precisam de ações que garantam a permanência do estudante na instituição, pois a ampliação da rede federal somadas a tais medidas trazem uma consequente mudança no perfil do estudante na instituição.

Conex. Ci. e Tecnol. Fortaleza/CE, v. 10, n. 1, p. 26 - 31, Março - 2016 


\section{METODOLOGIA}

A proposta de analisar a implementação da assistência estudantil na educação profissional e tecnológica surgiu com a atuação profissional como assistente social no Instituto Federal de Educação, Ciência e Tecnologia de São Paulo.

Este artigo compila alguns apontamentos, realizados a partir do estudo bibliográfico e documental acerca da temática em questão.

Almejou-se com a pesquisa teórica um maior conhecimento acerca da assistência estudantil, seus condicionantes, limites e possibilidades. Nesta perspectiva buscou-se para além do empirismo uma reflexão aprofundada sobre a assistência estudantil.

\section{RESULTADOS}

O decreto $\mathrm{n}^{\mathrm{o}} 7.234$ de 19 de julho de 2010 (BRASIL 2010) dispõe sobre o Programa Nacional de Assistência Estudantil - PNAES, que tem como finalidade ampliar as condições de permanência do estudante na educação pública federal.

O Programa de Apoio a Planos de Reestruturação e Expansão das Universidades Federais - REUN $]^{3}$ (BRASIL, 2007) e a implementação do programa nacional de assistência estudantil ocasionou uma crescente inserção de assistentes sociais nas instituições federais de ensino.

Executado no âmbito do Ministério da Educação MEC, o programa nacional de assistência estudantil, coloca no artigo $2^{\circ}$ do decreto que tem como objetivos democratizar as condições de permanência dos jovens na educação superior pública federal, minimizar os efeitos das desigualdades sociais e regionais na permanência e conclusão da educação superior, reduzir as taxas de retenção, evasão e contribuir para a promoção da inclusão social pela educação.

O programa nacional de assistência estudantil prevê a articulação com as atividades de ensino, pesquisa e extensão, sendo as ações desenvolvidas dentro das áreas de moradia estudantil, alimentação, transporte, atenção à saúde, inclusão digital, cultura, esporte creche, apoio pedagógico e acesso, participação e aprendizagem de estudantes com deficiência, transtornos globais do desenvolvimento e altas habilidades e superdotação. O decreto em seu artigo $4^{\circ}$ explica que:

As ações de assistência estudantil serão executadas por instituições federais de ensino superior, abrangendo os Institutos Federais de Educação, Ciência e Tecnologia, considerando suas especificidades, as áreas estratégicas

${ }^{3}$ O REUNI foi instituído pelo decreto $\mathrm{n}^{\circ} 6.096$, de 24 de abril de 2007 e tem o objetivo de criar condições para a ampliação do acesso e permanência na educação superior de ensino, pesquisa e extensão e aquelas que atendam às necessidades identificadas em seu corpo discente. (BRASIL 2010 p. 2).

É posto em parágrafo único que as ações de assistência estudantil considerem a necessidade de viabilizar a igualdade de oportunidades, contribuindo para melhoria do desempenho acadêmico e agindo preventivamente nas situações de retenção e evasão decorrentes da insuficiência de condições financeiras.

$\mathrm{O}$ decreto em seu artigo $5^{\circ}$ explica que "Serão atendidos no âmbito do PNAES prioritariamente estudantes oriundos da rede pública ou com renda familiar per capita de até um salário mínimo e meio, sem prejuízo de demais requisitos fixados pelas instituições federais de ensino superior"(BRASIL, 2010).

Sobre a definição de Assistência Estudantil, entende-se que o programa objetiva a efetivação da educação como direito social, fundamentando-se na equidade de oportunidade de permanência aos estudantes.

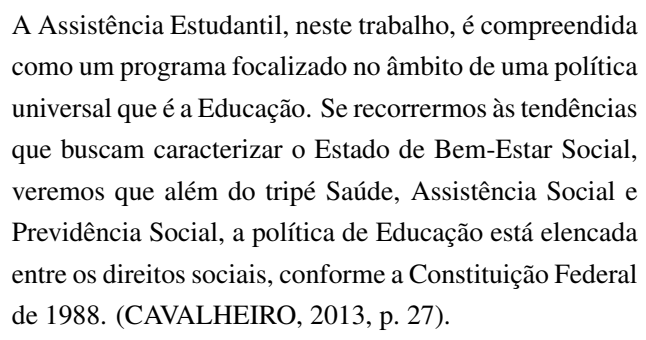

Os critérios, metodologia de seleção dos alunos, requisitos para a percepção de assistência estudantil, são definidos pela instituição federal de ensino, assim como mecanismos de acompanhamento e avaliação.

O orçamento destinado ao programa sofreu um considerável aumento desde 2010, ano de publicação do decreto que o regulamenta, ganhando um destaque entre as ações de combate a evasão escolar. O relatório de gestão, publicado anualmente, é um documento institucional que permite o acompanhamento dos recursos e ações desenvolvidas no Instituto Federal de Educação, Ciência e Tecnologia de São Paulo - IFSP. Assim este documento dispõe do recurso destinado ao programa,conforme a Tabela 1 .

O Programa Nacional de Assistência Estudantil PNAES está normatizado no IFSP através da resolução $n^{\circ} 135$ de 04/11/2014 (IFSP, 2014), que aprova o Regulamento da Política de Assistência Estudantil no Instituto Federal de Educação, Ciência e Tecnologia de São Paulo - IFSP, partindo da preocupação com a permanência do estudante no IFSP.

\footnotetext{
${ }^{4}$ Relatório de Gestão (2010, 2012 e 2013).

${ }^{5}$ LOA - Lei Orçamentária Anual (2011 e 2014).
} 
ASSISTÊNCIA ESTUDANTIL: A Implementação do Programa

Tabela 1: RECURSOS PARA O PROGRAMA DE ASSISTÊNCIA ESTUDANTIL - IFSP

\begin{tabular}{|l|c|}
\hline 2010 & $\mathrm{R} \$ 176.740,11$ \\
\hline 2011 & $\mathrm{R} \$ 5.577 .205,00$ \\
\hline 2012 & $\mathrm{R} \$ 6.996 .087,00$ \\
\hline 2013 & $\mathrm{R} \$ 9.761 .986,00$ \\
\hline 2014 & $\mathrm{R} \$ 15.482 .211,00$ \\
\hline
\end{tabular}

Fonte: Relatório de Gestão ${ }^{4}$ e Lei Orçamentária Anual ${ }^{5}$.

A seguinte resolução explica que para a implementação da Política de Assistência Estudantil - PAE é necessário a elaboração de um projeto de assistência estudantil por campus e que podem se inscrever os alunos regularmente matriculados no IFSP, após abertura de editais para seleção. No artigo $6^{\circ}$ é posto que:

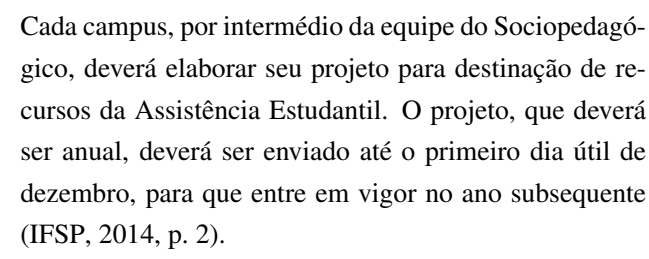

De acordo com o artigo $17^{\circ}$ do Regulamento da Política de Assistência Estudantil do IFSP, a estudantil no Instituto Federal de Educação, Ciência e Tecnologia de São Paulo destina-se ao atendimento de estudantes em vulnerabilidade social. Este documento foi aprovado pelo Conselho Superior em novembro de 2014. Nesta nova normatização foi ampliado o atendimento segundo o conceito de estudantes em situação de vulnerabilidade social.

Esta experiência de ampliação do conceito para atendimento dos estudantes foi uma demanda profissional dos assistentes sociais, que se articularam para a mudança no regulamento institucional.

Ao se abordar o conceito de vulnerabilidade social, é preciso pensá-lo em relação com a educação e com seu significado na implementação do Programa de Assistência Estudantil na referida instituição, como é exposto abaixo:

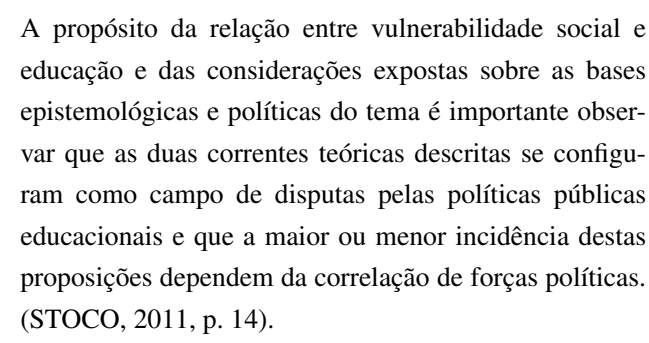

Nessa direção de disputa de forças políticas, a definição da renda per capita de atendimento e inclusão do estudante no programa de assistência estudantil em no máximo um salário mínimo e meio demonstra uma visão reducionista de um conceito mais amplo, já que a renda não é o único indicador ao se avaliar vulnerabilidade.

A resolução que dispõe sobre a Política de Assistência Estudantil é clara ao abordar a destinação ao estudante de acordo com a realidade de vulnerabilidade social. Os conceitos de vulnerabilidade e pobreza são distintos e requer uma apropriação para entendimento da assistência estudantil e sua efetivação na realidade dos estudantes.

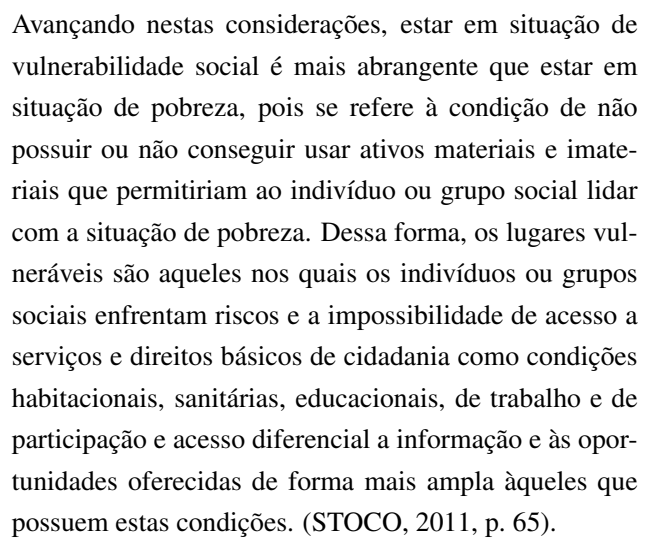

A Política Nacional de Assistência Social - PNAS, tida como referência na atuação dos profissionais de serviço social em diferentes políticas e campos de atuação, define vulnerabilidade social como:

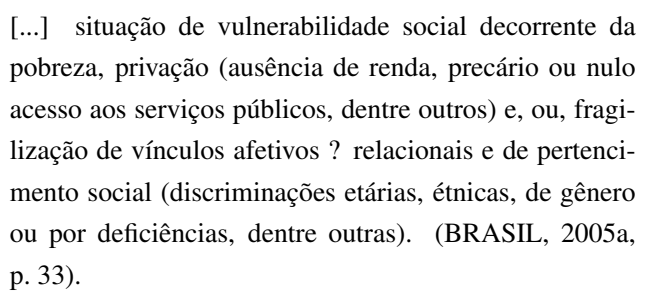
pobreza, privação (ausência de renda, precário ou nulo acesso aos serviços públicos, dentre outros) e, ou, fragilização de vínculos afetivos ? relacionais e de pertencimento social (discriminações etárias, étnicas, de gênero ou por deficiências, dentre outras). (BRASIL 2005a p. 33).

Partindo do princípio da equidade, o Programa Nacional de Assistência Estudantil tem como finalidade a permanência do educando no âmbito educacional, minimizando os índices de evasão escolar e garantindo assim o direito à educação. Assim, um dos principais objetivos do Programa de Assistência Estudantil é a diminuição da evasão escolar, que é uma das atuais preocupações da instituição, como destacado abaixo.

\footnotetext{
Os índices de evasão e os motivos pelos quais os estudantes abandonam seus cursos tem sido uma grande preocupação do IFSP. Apesar de ainda não ter os dados mensurados sobre esse tema e estudos sistematizados realizados sobre os motivos da evasão, o IFSP foi recentemente
} 
citado em um dos relatórios do Tribunal de Contas da União (TCU) pelo aferimento, por parte do órgão, da alta evasão escolar na instituição. O acórdão $n^{\circ}$ 506/2013 do TCU relata a auditoria realizada na Rede Federal de Educação Profissional e aponta necessidade de aprimoramentos nas atuações relacionadas à evasão escolar. (DAROS 2014 p. 94)

A implantação das ações de permanência e do programa nacional de assistência estudantil faz parte de uma intensa luta pela efetivação da educação como um direito social.

Essa realidade indica aspectos que precisam ser conhecidos e debatidos, principalmente relacionados à realidade social em que emergem. As políticas sociais nascem de um conflito econômico-político-social com o objetivo de enfrentamento da questão social e o real papel do Programa de Assistência Estudantil deve ser pensado e repensado a todo o momento para que este seja um agente de fortalecimento estudantil e de efetivação da política social da educação.

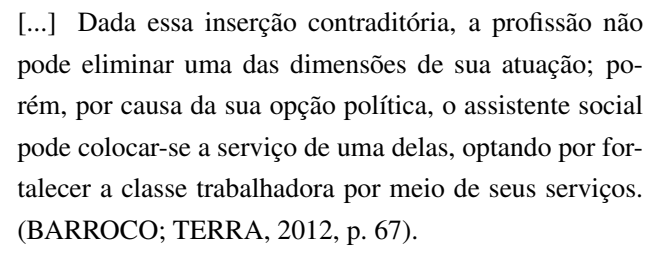

Essa conjuntura nos traz questionamentos das possibilidades e limites do programa nacional de assistência estudantil e das ações de permanência na atual contexto. Dentro do exposto, o Programa de Assistência Estudantil proveniente desta relação de contradição relacionada diretamente a fatores estruturais brasileiro 6 tem seu cerne na efetivação da política social de educação, objetivando a equidade social na permanência do estudante na instituição de ensino.

\section{CONCLUSÃO}

Um dos grandes desafios da implantação do programa nacional de assistência estudantil é a educação ser visualizada como direito social, favorecendo a formação dos estudantes e sua permanência na instituição.

O programa de assistência estudantil no IFSP considera a necessidade de viabilizar a igualdade de oportunidades, contribuindo para melhoria da vinculação do

\footnotetext{
6 "O aprofundamento das desigualdades sociais e a ampliação do desemprego atestam ser a proposta neoliberal vitoriosa, visto serem estas suas metas, ao apostar no mercado como a grande esfera reguladora das relações econômicas, cabendo aos indivíduos a responsabilidade de se virarem no mercado. Todo esse ideário, que envolve uma canalização do fundo público para interesses privados, cai como uma luva na sociedade brasileira [...]"(IAMAMOTO 2008 p. 141).
}

estudante com a instituição de ensino, com a melhoria do desempenho acadêmico e agindo preventivamente nas situações de retenção e evasão.

Para isso tem-se um longo caminho a percorrer no seu entendimento, conceituação e operacionalização, refletindo de que forma sua implantação segue na direção de uma concepção de educação emancipadora coerente com o projeto ético-político do profissional assistente social.

\section{REFERÊNCIAS}

BARROCO, M. L. S.; TERRA, S. H. Código de Ética do Assistente Social Comentado. Conselho Federal de Serviço Social - CFESS, (organizador). São Paulo: Cortez, 2012.

BRASIL. Política Nacional de Assistência Social. Brasília, 2005a.

Lei $n^{\circ} 11.096$, de 13 de janeiro de 2005.

Programa Universidade para Todos. Brasília, 2005b.

. Lei $n^{\circ}$ 6.096, de 24 de abril de 2007. Programa de Apoio a Planos de Reestruturação e Expansão das Universidades Federais. Brasília, 2007.

Decreto $n^{\circ}$ 7.234, de 19 de julho de 2010. Dispõe sobre o Programa Nacional de Assistência Estudantil. Brasília, 2010.

Lei $n^{\circ}$ 12.711, de 29 de agosto de 2012. Dispõe sobre o ingresso nas Universidades Federais e nas Instituições Federais de ensino técnico de nível médio e dá outras providências. Brasília, 2012a.

Decreto $n^{\circ} 7.824$, de 11 de outubro de 2012. Regulamenta a Lei $n^{\circ}$ 12.711, de 29 de agosto de 2012, que dispõe sobre o ingresso nas universidades federais e nas instituições federais de ensino técnico de nível médio. Brasília, 2012b.

Portaria Normativa $N^{\circ} 21$, de 5 de Novembro de 2012. Dispõe sobre o Sistema de Seleção Unificada Sisu. Brasília, 2012c.

Ministério do Planejamento, Orçamento e Gestão. Orçamento Federal ao Alcance de Todos: Projeto de Lei Orçamentária Anual - PLOA 2014. Brasília, 2013a.

Secretaria de Direitos Humanos da Presidência da República. Direito à Educação. Brasília, 2013b.

CAVAlHEIRO, J. S. O Programa Nacional de Assistência Estudantil nos Institutos Federais 
Gaúchos e o Trabalho do Assistente Social: alcances, perspectivas e desafios. Dissertação (Mestrado em Política Social) — Universidade Católica de Pelotas - Programa de Pós-Graduação em Política Social, Pelotas, 2013.

DAROS, M. A. O Instituto Federal de Educação, Ciência e Tecnologia de São Paulo (IFSP), a evasão escolar e a atuação do Serviço Social: uma experiência em construção (2008-2009). Dissertação (Mestrado) - Pontifícia Universidade Católica de São Paulo (PUC-SP), Saõ Paulo, 2014.

IAMAMOTO, M. V. Serviço Social em tempo de capital fetiche: Capital financeiro, trabalho e questão social. 2. ed. São Paulo: Cortez, 2008.

IFSP. Relatório de Gestão do Instituto Federal de Educação, Ciência e Tecnologia de São Paulo. São Paulo: [s.n.], 2013. Disponível em: <http://www. ifsp.edu.br/index.php/documentos-institucionais/ relatorio-de-gestao.html> Acesso em: 08 jul. 2013.

Resolução $n^{\circ} 135$, de 04 de novembro de 2014. Aprova a Política de Assistência Estudantil (PAE) do Instituto Federal de Educação, Ciência e Tecnologia de São Paulo - IFSP. São Paulo, 2014.

SEADE, F. Estudo da Fundação Seade analisa a evolução dos indicadores sociais paulistas entre 1993 e 2012. 2014. Disponível em: <http://www.seade.gov.br> Acesso em: 08 jun. 2014.

STOCO, S. Família, Educação e Vulnerabilidade Social: o caso da Região Metropolitana de Campinas. Tese (Doutorado em Educação) — Universidade Estadual de Campinas (UNICAMP) - Programa de Pós-Graduação em Educação, Campinas - SP, 2011. 